\title{
Panicle Blast and Canopy Moisture in Rice Cultivar Mixtures
}

\author{
You-Yong Zhu, Hui Fang, Yun-Yue Wang, Jin Xiang Fan, Shi-Sheng Yang, \\ Twng Wah Mew, and Christopher C. Mundt
}

First, second, and third authors: The Key Laboratory for Plant Pathology of Yunnan Province, Yunnan Agricultural University, Kunming 650201, China; fourth and fifth authors: Jianshui County Plant Protection Station of Yunnan Province, Jianshui 662200, China; sixth and seventh authors: Division of Entomology and Plant Pathology, International Rice Research Institute, DAPO Box 7777, Metro Manila, Philippines.

Current address of C. C. Mundt: Department of Botany and Plant Pathology, 2082 Cordley Hall, Oregon State University, Corvallis 97331. Accepted for publication 14 December 2004.

\begin{abstract}
Zhu, Y.-Y., Fang, H., Wang, Y.-Y., Fan, J. X., Yang, S.-S., Mew, T. W., and Mundt, C. C. 2005. Panicle blast and canopy moisture in rice cultivar mixtures. Phytopathology 95:433-438.

Glutinous rice cultivars were sown after every fourth row of a nonglutinous, hybrid cultivar in an additive design. The glutinous cultivars were 35 to $40 \mathrm{~cm}$ taller and substantially more susceptible to blast than was the nonglutinous cultivar. Interplanting of glutinous and nonglutinous rice reduced the incidence and severity of panicle blast on the glutinous cultivars by $>90 \%$, and on the nonglutinous cultivar by 30 to $40 \%$. Mixing increased the per unit area yield of glutinous rice by 80 to $90 \%$

heights and canopy structures may contribute to a microclimate that is less favorable to blast infection, we monitored the moisture status of the glutinous cultivars in pure stand and mixture at $0800 \mathrm{~h}$ by measuring relative humidity at the height of the glutinous panicles using a swing psychrometer and by visually estimating the percentage of leaf area covered by dew. Averaged over the two seasons, the number of days of $100 \%$ humidity at $0800 \mathrm{~h}$ was 20.0 and 2.2 for pure stands and mixtures, respectively. The mean percentage of glutinous leaf area covered by dew was 84 and $36 \%$ for the pure stands and mixtures, respectively. Although other mechanisms also were operative, reduced leaf wetness was likely a substantial contributor to panicle blast control in the mixtures.
\end{abstract} relative to pure stand, whereas yield of the nonglutinous cultivar was essentially unaffected by mixing. To determine whether the different plant

Multiline cultivars and cultivar mixtures have been shown to impact a spectrum of plant diseases $(19,25)$, and their commercial use is increasing $(9,11)$. Much has been learned of the epidemiological mechanisms affecting disease in mixtures $(5,9,11,19$, 20,27). For specialized pathogens, such as rusts and powdery mildews, the most important mechanism may be inoculum dilution caused by the increased distance between plants of same genotype, with induced resistance and barrier effects playing an increasing role later in the growing season $(7,27)$.

Most published work with mixtures has been oriented toward industrialized agriculture, where some degree of crop uniformity is desired. Thus, mixture components often are chosen to be similar for important agronomic traits and are mixed in a "replacement" design, where plant density is the same in both mixtures and pure stands. In other situations, however, greater phenotypic diversity may be present, and this may make disease control mechanisms more complex. For example, differences in morphology among mixture components might alter canopy microclimate. Mixing more diverse plant genotypes or mixing in an addition approach (overall plant density higher in mixtures than in pure stands) may increase the degree of intergenotypic competition which, in turn, may alter plant susceptibility to disease (10).

Blast, caused by Magnaporthe grisea, is an important disease of rice throughout the world (22). The pathogen causes necrotic lesions on both leaves and panicles. Panicle blast is considered the more important phase of the disease because it is more closely related to yield loss, and severe panicle blast sometimes can occur without being preceded by severe leaf blast. Resistance to rice

Corresponding author: Y. Y. Zhu; E-mail address: yppl@ public.km.yn.cn

DOI: 10.1094/PHYTO-95-0433

(C) 2005 The American Phytopathological Society
Additional keyword: microenvironment.

blast is notoriously short lived $(3,14)$, and there is need for improved management strategies (17) to increase durability of resistance. Multiple studies have shown that multiline cultivars and cultivar mixtures can provide substantial reduction of both leaf and panicle blast $(15,18)$, and rice cultivar mixtures are used commonly in subsistence agriculture in some parts of the world (2). Rice cultivar mixtures recently have been used to control blast in Yunnan Province China, with great success. In this application, a susceptible, glutinous cultivar is mixed with a more resistant, nonglutinous cultivar in an additive design, with one row of the glutinous cultivar being added after every fourth row of the more resistant, nonglutinous cultivar. Four mixtures were tested in contiguous rice fields covering areas of 812 and 3,342 ha in 1998 and 1999, respectively. Mixtures reduced panicle blast severity on the susceptible component by $94 \%$, increased overall rice productivity by $17 \%$, and eliminated the need for fungicides in the second year of the study. Use of this mixture practice expanded to 1 million ha by 2004 (unpublished data), and has resulted in substantial societal benefits (16).

It has been suggested that mixtures are more effective in controlling disease when deployed at large spatial scale $(19,27)$, and the success of rice cultivar mixtures in China has been attributed to the spatial scale of that study (31). There are other potential explanations for success of that mixture system, however. The purpose of the present study is to determine whether height differences between mixture components alter canopy moisture, potentially rendering the microenvironment less conducive for blast.

\section{MATERIALS AND METHODS}

Rice cultivars. Two glutinous, nonhybrid cultivars (Huangkenuo and Zinuo) and one nonglutinous, hybrid cultivar (Shanyou63) were used. The glutinous cultivars were 35 to $40 \mathrm{~cm}$ 
taller, 7 to 10 days later in maturity, and had $\approx 60 \%$ less yield potential in absence of disease. When these cultivars were inoculated in the greenhouse with 29 isolates representative of the local $M$. grisea population, the mean virulence frequency was 86.2 and $13.8 \%$ for the glutinous and nonglutinous cultivars, respectively. The nonglutinous cultivar consistently showed much less blast under field conditions (unpublished data).

Treatments and experimental design. The five treatments included pure stands of the three rice cultivars and a row mixture of each of the glutinous cultivars with the nonglutinous one. A completely random design was used because of uniform field conditions, and there were five replications per treatment. In the mixtures, a glutinous rice cultivar was sown after every fourth row of the nonglutinous cultivar in an additive design (Fig. 1). Row spacings and hill densities were similar to those used by farmers in Yunnan Province. Pairing of rows is done to provide alleys for the movement of laborers. Each plot was 4 by $5 \mathrm{~m}$, with $1.5 \mathrm{~m}$ of the nonglutinous cultivar planted between adjacent plots and $10 \mathrm{~m}$ around the entire experiment. The experiment was conducted in Xiejiawan Village, Jianshui County, Yunnan Province in 2000 and 2001.

Planting method and crop management. Seedlings were transplanted into the field in April in hills of four to five plants for the glutinous cultivars and one plant per hill for the nonglutinous cultivar. The number of tillers per hill were approximately equivalent for the glutinous and nonglutinous cultivars, however, because the nonglutinous cultivar (hybrid) produces 14 to 20 tillers per plant whereas the glutinous cultivars (traditional) produce only 3 to 4 tillers per plant. All plots were managed by research staff and treated in the same manner as the surrounding mixed cultivar plantings in farmers' fields. No fungicides were applied to control blast.

Disease assessments. Plots were assessed for the severity of blast symptoms, expressed as the percentage of panicle branches that were necrotic due to the effects of $M$. grisea. The disease was assessed at five sampling points in each plot, distributed in a uniform pattern. For pure stand plots, four hills were evaluated at each sampling point, randomly sampling 20 tillers from each point, for a total of 100 panicles evaluated per plot. For mixed plots, four hills of each cultivar (glutinous and nonglutinous) were evaluated at each point, randomly sampling 40 tillers (20 tillers from glutinous rice and 20 tillers from nonglutinous rice) at each point, for a total of 200 panicles evaluated per plot. The survey time was mid-August, when both cultivars were physiologically mature (about 7 to 10 days before harvest), and there was no further disease development subsequently.

Each sampled panicle was visually examined by experienced personnel to estimate the percentage of branches that were necrotic due to infection by $M$. grisea (1). Each panicle was given a rating from 0 to 5 , where $0=$ no disease, $1=<5 \%$ of panicle branches necrotic, $2=5$ to $30 \%$ of panicle branches necrotic, $3=$ 31 to $50 \%$ of panicle branches necrotic, $4=51$ to $99 \%$ of branches necrotic, and $5=100 \%$ of branches necrotic. Disease incidence was considered to be the percentage of panicles showing any level of panicle blast. Disease severity was summarized within each plot as $\left(\left[\left(n_{1} \times 1\right)+\left(n_{2} \times 2\right)+\left(n_{3} \times 3\right)+\left(n_{4} \times 4\right)+\right.\right.$ $\left.\left.\left(n_{5} \times 5\right)\right] / \Sigma n_{0} \ldots n_{5} \times 5\right) \times 100$, where $n_{0} \ldots n_{5}$ is the number of culms in each of the respective disease categories. Thus, a disease severity of $0 \%$ would indicate no disease and $100 \%$ would indicate that $100 \%$ of panicle branches were necrotic. This method was utilized because it is very familiar to fieldworkers in China, even though disease categories are not balanced and could introduce some bias.

Humidity and dew measurement. A $1.6-\mathrm{m}$ wooden pole was placed in the center of each plot. A wet bulb/dry bulb psychrometer (Fuyang Meter Factory, Wuqiang County, China) was attached to each pole at the same height as the panicle neck of the glutinous cultivar $(\approx 1.4 \mathrm{~m}$ above ground level) in each glutinous pure stand and in each mixture plot. In both pure stands and mixtures, the psychrometer was placed between two adjacent hills of glutinous rice. Beginning at 50 days after transplanting, the relative humidity in each plot was recorded at $0800 \mathrm{~h}$ each day. The percentage of the upper leaf surfaces that was covered with dew was estimated visually for the uppermost leaf of 20 tillers in each of five hills of glutinous rice near the pole of each plot every 6 days, also at approximately $0800 \mathrm{~h}$. This was done on a continuous scale from 0 to $100 \%$. Estimates were made quickly to avoid the drying effect of the rising sun, and without touching leaves so as to avoid dislodging dew from the leaf surfaces. The survey period was from 11 June to 7 August 2000 and 15 June to 11 August 2001. Panicle height increased $\approx 5$ to $10 \mathrm{~cm}$ during the assessment period.

Crop yield. Each plot was harvested by hand, threshed, and weighed. For mixtures, the two cultivars were harvested, weighed, and threshed separately. For the purpose of comparison with pure stands, the yields of the glutinous cultivars in mixture were adjusted to the per-hectare pure stand equivalent (i.e., the perhectare yield that would result if the per-hill yield in pure stand was the same as the per-hill yield in mixture). This was done by multiplying the grain yield of the glutinous cultivar in each mixture plot by four, because there were one-fourth as many hills of glutinous rice per hectare in the mixtures compared with the glutinous pure stands. This transformation was unnecessary for the nonglutinous cultivar, because it was grown at the same density in both pure stand and mixture.

Statistical analyses. Each plot was considered to be an experimental unit, and data were subjected to analysis of variance (ANOVA) using SAS (SAS Institute, Cary, NC) or Excel (Microsoft Corp., Seattle, WA). Five separate ANOVAs were conducted for each year, one for each of the following dependent variables: panicle blast incidence, panicle blast severity index, mean percent dew coverage over the sampling period, mean relative humidity over the sampling period, and number of days at $100 \%$ relative humidity over the sampling period.

Data sets for the disease variables and yield did not consist of a full factorial, because glutinous + glutinous and nonglutinous +

\begin{tabular}{|c|c|c|c|c|c|c|c|}
\hline \multicolumn{4}{|c|}{$\mathbf{A}$} & \multicolumn{4}{|c|}{ B } \\
\hline o & o & O & o & $\mathrm{x}$ & $\mathrm{X}$ & $\mathrm{x}$ & $\mathrm{x}$ \\
\hline \multirow{3}{*}{ o } & & & & $\mathrm{x}$ & $\mathrm{X}$ & $\mathrm{x}$ & $\mathrm{X}$ \\
\hline & o & o & o & $\mathbf{x}$ & $\mathbf{X}$ & $\mathrm{x}$ & $\mathrm{X}$ \\
\hline & & & $30 \mathrm{~cm}$ & $\mathbf{x}$ & $\mathbf{X}$ & $\mathrm{x}$ & $x$ \\
\hline O & o & o & o & $\mathrm{x}$ & $\mathbf{X}$ & $\mathrm{x}$ & $x^{15 \mathrm{~cm}}$ \\
\hline
\end{tabular}

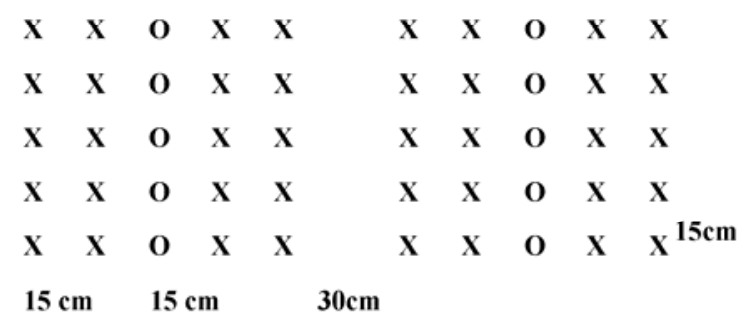

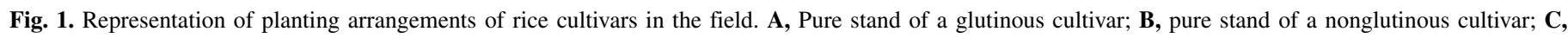
mixture of a glutinous and a nonglutinous cultivar; $\mathrm{O}$ indicates a hill of glutinous rice; and $\mathrm{X}$ indicates a hill of nonglutinous rice. 
nonglutinous mixtures were not included. Thus, ANOVA models (for a completely random design) consisted only of the factors "treatment" and "error". Disease variables and yield for each of the two cultivars in mixture were considered to be separate treatments, resulting in a total of seven treatments. Comparisons of disease or yield variables between cultivars in the same mixture were not made because the disease or yield of cultivars in the same mixture could be correlated, thus biasing analyses, and because these comparisons were not of significant biological interest for this study. For each ANOVA, four single-degree-offreedom linear contrasts from within treatment sums of squares were used to compare each cultivar in mixture with its performance in pure stand.

The microclimate data were collected only for the glutinous cultivar, providing a complete factorial of two levels of diversity (pure stand or mixture) and two levels of cultivar (Huangkenou or Zinou). Thus, a two-by-two factorial ANOVA was conducted for each of the three moisture variables (percent dew coverage, mean relative humidity, and mean number of days at $100 \%$ humidity) for each of the 2 years of the experiment. A significant main effect of diversity was considered to indicate an effect of mixing on the moisture variable. Prior to analysis, microclimate data were averaged over dates of collection so as to eliminate autocorrelation among data collected within the same plot on different days.

The mean percent dew coverage was correlated with the mean percent relative humidity and with the mean number of days at $100 \%$ relative humidity (in all cases, data first were averaged over all sampling dates for each plot) using Excel (Microsoft Corp.), and incorporating data from both years and all treatments.

\section{RESULTS}

There was moderately high disease pressure in both years of the study, with panicle blast incidence and the severity index on glutinous pure stands approaching 90 and 50\%, respectively (Table 1). Mixing cultivars had a substantial impact on panicle blast levels. Mixing decreased panicle blast incidence and the severity index on the glutinous cultivars by $>90 \%$ compared with their component pure stands. Incidence and severity on the nonglutinous cultivar was reduced by 30 to $40 \%$, though reductions of the severity index were not always statistically significant $(P=$ 0.05) (Table 1).

Diversification clearly impacted moisture status of the glutinous cultivars. Relative humidity varied during the season, starting at $<90 \%$ and increasing as the season progressed (Fig. 2). The greatest differences in relative humidity between pure stands and mixtures occurred later in the season, the time at which panicle blast infections occur. Averaged over the two seasons, the number of days of $100 \%$ humidity at $0800 \mathrm{~h}$ was 20.0 and 2.2 for pure stands and mixtures, respectively. Throughout the season, dew coverage on the glutinous cultivars in mixture was less than half of that when grown in pure stand (Fig. 3). For both mixtures and years, the mean percent dew coverage at $0800 \mathrm{~h}$, the number of days with $100 \%$ humidity at $0800 \mathrm{~h}$, and the mean relative humidity at $0800 \mathrm{~h}$ were significantly $(P<0.0001)$ less in mixture than in pure stand (main effect of diversity) (Table 2), suggesting that the three measures of moisture correspond well. A combined correlation analysis incorporating all treatments and both years indicates that percent dew coverage and percent relative humidity were highly correlated $(R=0.834, P<0.0001, N=100)$, as was percent dew coverage and number of days at $100 \%$ humidity $(R=$ 0.956, $P<0.0001, N=100)$.

The cultivar-diversity interaction for percent dew coverage was not significant in either year $(P>0.75)$. The cultivar-diversity interaction was significant $(P<0.012)$ for both relative humidity measures and in both years (Table 2). The mean square for the main effect of diversity was substantially greater than the cultivar-diversity interaction in all cases, however. Thus, the diversity main effect was considered to be a valid test of the effect of mixtures versus pure stands on relative humidity. Dew coverage, blast incidence, and blast severity were not observed to vary spatially within plots, thus allowing for a comparison between disease readings, which were spread throughout the plots, and the dew and relative humidity measurements, which were obtained near the central pole of each plot.

The per-hectare equivalent yield of the glutinous rice cultivars was nearly double in mixture compared with pure stand. At the

TABLE 1. Panicle blast incidence, panicle blast severity index, and grain yield of glutinous and nonglutinous rice cultivars grown in pure stands and mixtures in Yunnan Province, China

\begin{tabular}{|c|c|c|c|c|c|c|c|}
\hline \multirow[b]{2}{*}{ Year, treatment ${ }^{\mathrm{c}}$} & \multirow[b]{2}{*}{ Cultivard $^{\mathrm{d}}$} & \multicolumn{2}{|c|}{ Incidence $^{\mathrm{a}}$} & \multicolumn{2}{|c|}{ Severity index ${ }^{b}$} & \multicolumn{2}{|c|}{ Yield } \\
\hline & & Percent & $P>F^{\mathrm{e}}$ & Percent & $P>F^{\mathrm{e}}$ & $\mathrm{kg} / \mathrm{ha}^{\mathrm{f}}$ & $P>F^{\mathrm{e}}$ \\
\hline \multicolumn{8}{|l|}{2000} \\
\hline $\mathrm{H}$ & $\mathrm{H}$ & 88.7 & & 47.9 & & 2,339 & \\
\hline $\mathrm{Z}$ & Z & 80.0 & 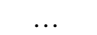 & 38.8 & 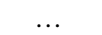 & 2,106 & \\
\hline $\mathrm{Z}+\mathrm{S}$ & $\mathrm{Z}$ & 6.1 & 0.0001 & 3.8 & 0.0001 & 4,041 & 0.0001 \\
\hline $\mathrm{S}$ & $\mathrm{S}$ & 5.8 & & 2.9 & & 8,149 & \\
\hline \multicolumn{8}{|l|}{2001} \\
\hline $\mathrm{H}$ & $\mathrm{H}$ & 91.1 & $\ldots$ & 51.9 & 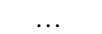 & 2,344 & \\
\hline $\mathrm{H}+\mathrm{S}$ & $\mathrm{H}$ & 6.7 & 0.0001 & 4.5 & 0.0001 & 4,345 & 0.0001 \\
\hline $\mathrm{Z}$ & $\mathrm{Z}$ & 83.2 & $\ldots$ & 40.6 & $\ldots$ & 2,098 & $\ldots$ \\
\hline$Z+S$ & $\mathrm{Z}$ & 5.6 & 0.0001 & 3.7 & 0.0001 & 3,997 & 0.0001 \\
\hline $\mathrm{S}$ & $\mathrm{S}$ & 5.8 & $\ldots$ & 2.9 & $\ldots$ & 8,154 & \\
\hline
\end{tabular}

${ }^{a}$ Percentage of tillers showing any degree of panicle necrosis.

${ }^{\mathrm{b}}$ Index: $0=$ no panicle blast; $100=100 \%$ of panicle branches necrotic.

${ }^{\mathrm{c}} \mathrm{H}=$ glutinous cv. Huangkenou; $\mathrm{Z}=$ glutinous cv. Zinou; $\mathrm{S}=$ nonglutinous cv. Shanyou63; + indicates a mixture of two cultivars; MSE = mean square error, with 34 degrees of freedom, from analysis of variance for a completely random design with seven treatments and five replications.

${ }^{\mathrm{d}}$ Cultivar upon which disease and yield were measured in a given treatment.

e Significance of linear contrast for cultivar performance in mixture versus pure stand.

${ }^{\mathrm{f}}$ Yield of glutinous cultivars in mixtures were adjusted to the per hectare pure stand equivalent (i.e., the per-hectare yield that would result if the per-hill yield in pure stand was the same as the per hill yield in mixture). 
same time, the yield of nonglutinous rice was essentially unaffected by mixing (Table 1 ).

\section{DISCUSSION}

Given that free moisture is crucial for infection by $M$. grisea $(8,13,23,26,29,30)$, the very substantial reductions in dew coverage and number of mornings with $100 \%$ humidity observed in the mixtures could have resulted in consistently large reductions in blast levels. Large differences in height between cultivars in the mixtures could have allowed for increased air circulation and light penetration to the highly susceptible, glutinous cultivars in the mixture, thus reducing moisture levels. It is practical to include such height diversity in Yunnan Province, because harvest is entirely by hand. In contrast, plant genotypes included in multiline cultivars and cultivar mixtures used in mechanized agriculture often are selected for some degree of phenotypic uniformity (19).

We used two measures of leaf wetness, neither of which provides a complete description of canopy moisture status. Moisture was measured at only a single time in the morning, when moisture status might be expected to be in transition. In contrast, moisture differences between pure stands and mixtures may not have been so large if measured during the night. Successful infection by $M$. grisea requires eight or more hours of leaf wetness $(13,26)$. Thus, extending the dew period into the morning hours can be a critical factor driving severe development of blast $(8,23)$. Another complication is that dew was estimated on leaves whereas blast was measured on panicles, the most serious phase of the disease. Dew was measured on leaves simply because moisture would not be easily observable on panicles. On the other hand, relative humidity data were taken at the height of panicles, and were highly correlated with dew estimates on leaves. Ideally, we would have measured leaf wetness and humidity at multiple positions in the canopy and on a 24-h basis, but such resources were unavailable at the time this study was conducted. Overall, our goal was not to measure all wetness variables that contributed to infection but, rather, to determine whether moisture status in mixtures compared with pure stands differed sufficiently to potentially be a substantial contributor to the blast control observed in the mixtures.

In addition to moisture effects, other mechanisms likely also contributed to the consistently high levels of disease control provided by the mixtures. Increased spacing among hills of the glutinous cultivar in mixtures compared with pure stands would have provided a significant dilution effect, which often may be the most important mechanism of disease control operating in mixtures $(7,27)$. The different cultivars of rice were mixed by rows rather than being mixed randomly. This approach was used because the glutinous and nonglutinous cultivars have different maturity dates and end uses and, therefore, must be harvested separately. Also, random mixtures of a tall, lower-yielding cultivar with a semidwarf, high-yielding cultivar sometimes can result in reduced yield owing to shading effects (12). A result of using row mixtures is to increase the genotype unit area (GUA) of the crop (i.e., the ground area occupied by an independent, genetically homogeneous unit of host tissue) (20). A larger GUA will increase the amount of autoinfection (24), potentially reducing the effectiveness of a mixture for disease control (19). The row mixtures in our study provided levels of disease control greater than that found for most studies of random mixtures of plants (25), despite the increased GUA. Several comparisons have shown row mixtures to be less effective in controlling disease than random mixtures $(4,15,21)$, but a comparison to random mixtures was not

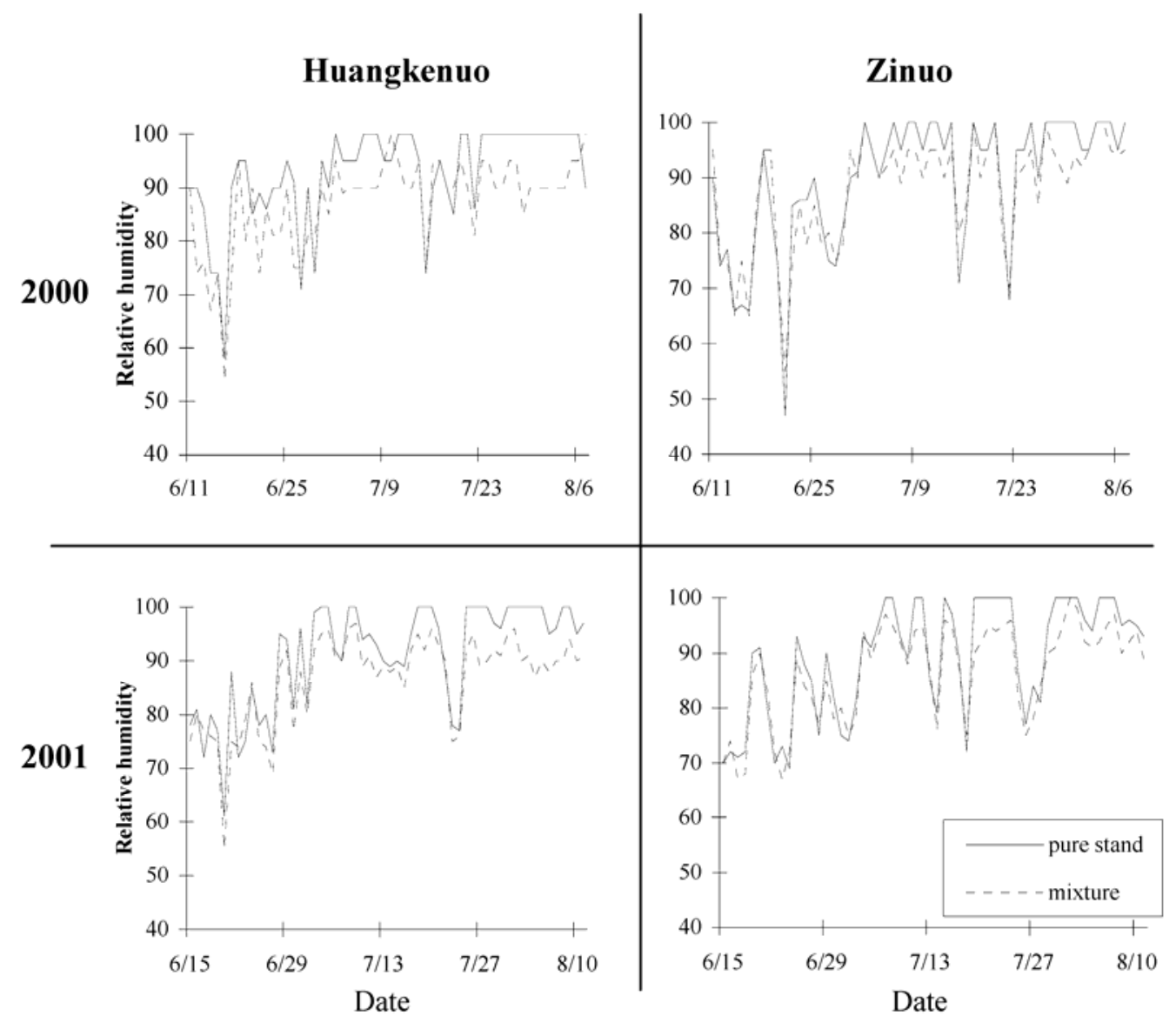

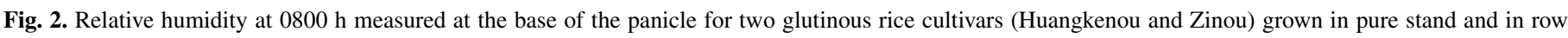
mixtures with a shorter nonglutinous cultivar (Shanyou63) in 2 years. Each data point is the mean of five replications. 
included in our study. It is likely that other mechanisms, such as microenvironment influences, were sufficiently large to mask any obvious negative effect of GUA in our study.

Although disease levels were low even in pure stands of the nonglutinous cultivar, there was a consistent reduction in disease incidence and severity index on that cultivar in mixtures compared with pure stands. This effect is unlikely to be due to moisture effects, given that the nonglutinous cultivar was transplanted at the same density and yielded approximately the same in both mixtures and pure stand. Given that the glutinous and nonglutinous cultivars react differently to different races of $M$. grisea, induced resistance may be at least partially responsible for the disease reductions on the nonglutinous component of the mixtures. It has been suggested that induced resistance is a significant, though not the most important, mechanism of blast control in rice multiline cultivars (15). It also is conceivable that height differences between cultivars in the mixtures altered wind patterns in a manner that reduced the spread of blast.
An evaluation of mixture yield in this study is complicated by several factors. Mixtures were constructed in an additive design, where a limited number of glutinous hills were added to the full pure stand density of the nonglutinous cultivar. The yield potential of the nonglutinous cultivar is substantially greater than that of the glutinous cultivars. Disease levels differed in the pure stands versus mixtures and among the cultivars when grown in pure stand. Finally, disease levels on the three cultivars were affected to different degrees by mixing. The per-hectare yield of the nonglutinous cultivar was essentially the same in the mixture as in pure stand. The glutinous cultivar was added to the mixture at $25 \%$ of the pure stand density, but the per-hill yield of the glutinous cultivars was 80 to $90 \%$ greater in mixture than in pure stand. The end result was for the glutinous rice production in mixture to be essentially a "bonus" on top of the nonglutinous yield that a farmer would normally obtain in pure stand.

The first research on the use of intraspecific diversity for disease control was with multiline cultivars containing lines bred

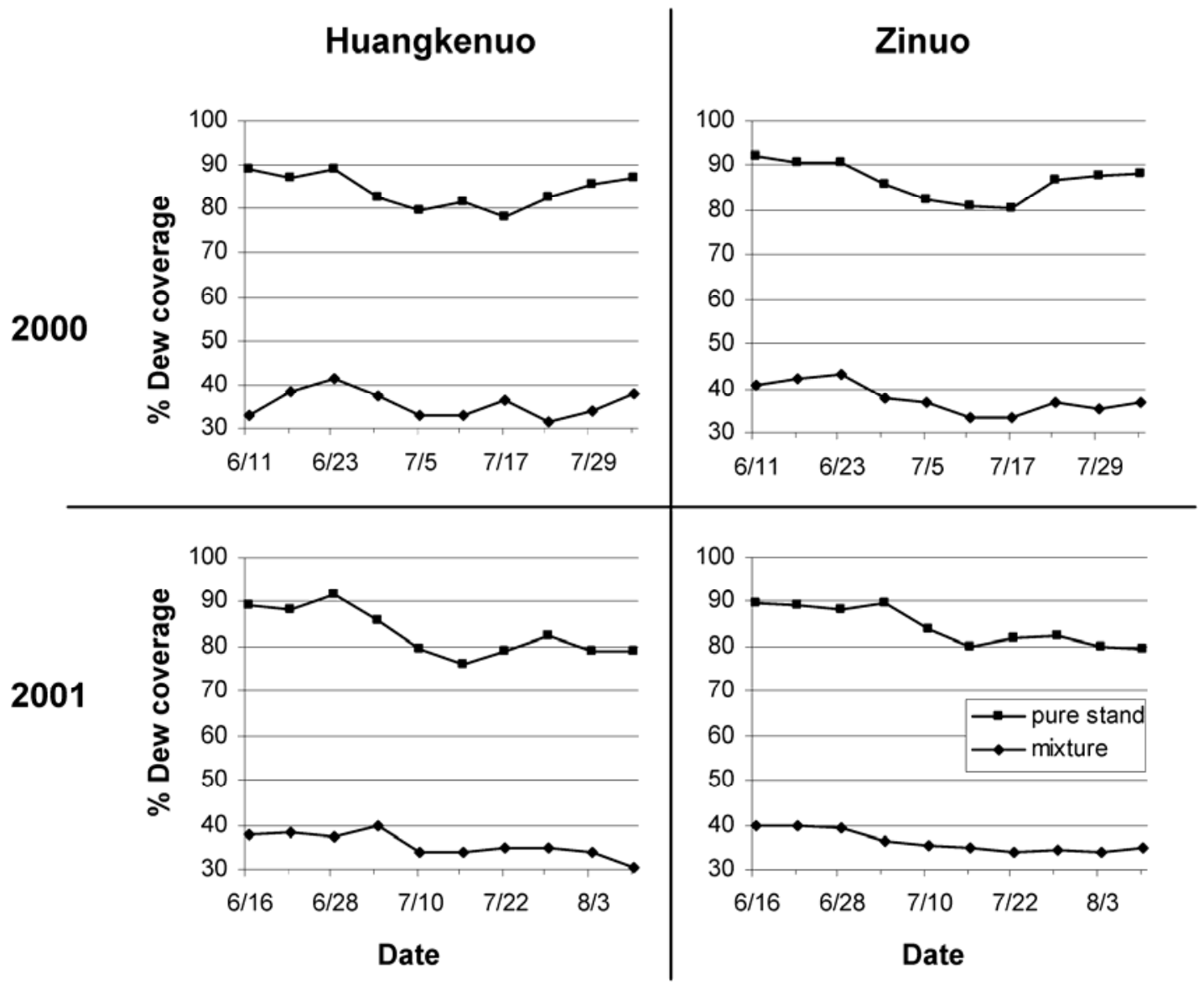

Fig. 3. Percentage of the upper leaf surfaces that were covered with dew for the uppermost leaves at $0800 \mathrm{~h}$ for two glutinous rice cultivars (Huangkenou and Zinou) grown in pure stand and in row mixtures with a shorter nonglutinous cultivar (Shanyou63) in 2 years. Each data point is the mean of five replications.

TABLE 2. Analysis of variance for moisture variables at 0800 h, averaged over 57 days in each of 2000 and 2001 for relative humidity (RH) and every 6 days for dew coverage

\begin{tabular}{|c|c|c|c|c|c|c|c|c|c|c|c|c|c|}
\hline \multirow[b]{3}{*}{ Source $^{\mathrm{a}}$} & \multirow[b]{3}{*}{ df } & \multicolumn{4}{|c|}{ Mean RH } & \multicolumn{4}{|c|}{ Number of days at $100 \% \mathrm{RH}$} & \multicolumn{4}{|c|}{ Coverage by dew (\%) } \\
\hline & & \multicolumn{2}{|c|}{2000} & \multicolumn{2}{|c|}{2001} & \multicolumn{2}{|c|}{2000} & \multicolumn{2}{|c|}{2001} & \multicolumn{2}{|c|}{2000} & \multicolumn{2}{|c|}{2001} \\
\hline & & MS & $P>F$ & MS & $P>F$ & MS & $P>F$ & MS & $P>F$ & MS & $P>F$ & MS & $P>F$ \\
\hline D & 1 & 65.0 & $<0.0001$ & 62.3 & $<0.0001$ & $1,155.0$ & $<0.0001$ & $1,496.4$ & 0.0001 & 11,897 & $<0.0001$ & 11,448 & $<0.0001$ \\
\hline $\mathrm{C} \times \mathrm{D}$ & 1 & 18.3 & $<0.0001$ & 3.5 & 0.0029 & 80.0 & $<0.0001$ & 26.4 & 0.0120 & 0.072 & 0.9050 & 0.612 & 0.7590 \\
\hline Error & 16 & 0.014 & $\ldots$ & 0.286 & $\ldots$ & 31.6 & $\ldots$ & 3.3 & $\ldots$ & 4.9 & $\ldots$ & 6.3 & $\ldots$ \\
\hline
\end{tabular}

${ }^{\text {a }}$ Source of variation. $\mathrm{C}=$ main effect of the cv. Huangkenou versus the cv. Zinou and $\mathrm{D}=$ main effect of whether a cultivar was grown in pure stand versus mixture. 
to be uniform for important agronomic traits (5). This approach avoided concerns about lack of phenotypic uniformity within fields (6). Later, as diversity became more accepted, the favored approach was to mix phenotypically similar cultivars within a field, with no attempt to breed for uniformity (27). The additional background diversity present in cultivar mixtures sometimes can provide advantages for disease control, yield, and yield stability $(19,27,28)$. The greater morphological diversity between cultivars in this study may have provided even greater benefits to disease control and yield. It is important to note, however, that the rice mixtures discussed in this article were chosen from among less successful ones, and required critical input from farmers to find highly useful combinations and spatial patterns of cultivars.

\section{ACKNOWLEDGMENTS}

We thank B. Anacker and L. Wallace for help with data analyses.

\section{LITERATURE CITED}

1. Anonymous. 1996. Rules For Investigation and Forecast of the Rice Blast. The State Standard of the People's Republic of China, No. GB/T 157901995. China Standard Press, Beijing.

2. Bonman, J. M., Estrada, B. A., and Denton, R. I. 1986. Blast management with upland rice cultivars. Pages 375-382 in: Proc. Symp. Progress in Upland Rice Research. Int. Rice Res. Inst., Los Banos, Philippines.

3. Bonman, J. M., Khush, G. S., and Nelson, R. J. 1992. Breeding rice for resistance to pests. Annu. Rev. Phytopathol. 20:507-528.

4. Brophy, L. S., and Mundt, C. C. 1991. Influence of plant spatial patterns on disease dynamics, grain yield and plant competition in genetically diverse wheat populations. Agric. Ecosyst. Environ. 35:1-12.

5. Browning, J. A., and Frey, K. J. 1969. Multiline cultivars as a means of disease control. Annu. Rev. Phytopathol. 14:355-382.

6. Browning, J. A., and Frey, K. J. 1981. The multiline concept in theory and practice. Pages 37-46 in: Strategies for the Control of Cereal Disease. J. F. Jenkyn and R. T. Plumb, eds. Blackwell, Oxford.

7. Chin, K. M., and Wolfe, M. S. 1984. The spread of Erysiphe graminis f. sp. hordei in mixtures of barley varieties. Plant Pathol. 33:89-100.

8. Dong, J. G., Dong, J., Li, H. L., Wang, J. M., Ding, A. Y., Chen, J., Zhu, J. H., Wang, W., Li, B. D., and He, Y. Q. 2001. Agricultural Plant Pathology, Northern, ed. China Agricultural Press, Beijing.

9. Finckh, M. R., Gacek, E. S., Goyeau, H., Lannou, C., Merz, U., Mundt, C. C., Munk, L., Nadziak, J., Newton, A. C., de Vallavieille-Pope, C., and Wolfe, M. S. 2000. Cereal variety and species mixtures in practice. Agronomie 20:813-837.

10. Finckh, M. R., and Mundt, C. C. 1992. Plant competition and disease in genetically diverse wheat populations. Oecologia 91:81-92.

11. Garrett, K. A., and Mundt, C. C.1999. Epidemiology in mixed host populations. Phytopathology 89:984-990.
12. Jennings, P. R., and Aquino, R. C. 1968. Studies on competition in rice: III. The mechanism of competition among phenotypes. Evolution 22:529542.

13. Kingsolver, C. H., Barksdale, T. H., and Marchetti, M. A. 1984. Rice blast epidemiology. Penn. State Univ. Coll. Agric. Bull. 853.

14. Kiyosawa, S. 1982. Genetics and epidemiological modeling of breakdown of plant disease resistance. Annu. Rev. Phytopathol. 20:93-117.

15. Koizumi, S. 2001. Rice blast control with multilines in Japan. Pages 143 157 in: Exploiting Biodiversity for Sustainable Pest Management. Proc. Impact Symp. Exploiting Biodiversity for Sustainable Pest Management, Kunming, China. T. W. Mew, E. Borromeo, and B. Hardy, eds. Int. Rice Res. Inst., Los Banos, Philippines.

16. Leung, H., Zhu, Y., Revilla-Molina, I., Fan, J. X., Chen, H., Pangga, I., Vera Cruz, C., and Mew, T. W. 2003. Using genetic diversity to achieve sustainable rice disease management. Plant Dis. 87:1156-1169.

17. Mundt, C. C. 1994. Techniques to manage pathogen co-evolution with host plants to prolong resistance. Pages 193-205 in: Rice Pest Science and Management. P. S. Teng, K. L. Heong, and K. Moody, eds. Int. Rice Res. Inst., Los Banos, Philippines.

18. Mundt, C. C. 1994. Use of host genetic diversity to control cereal diseases: Implications for rice blast. Pages 293-307 in: Rice Blast Disease. S. Leong, R. S. Zeigler, and P. S. Teng, eds. CABI, Cambridge.

19. Mundt, C. C. 2002. Use of multiline cultivars and cultivar mixtures for disease management. Annu. Rev. Phytopathol. 40:381-410.

20. Mundt, C. C., and Browning, J. A. 1985. Development of crown rust epidemics in genetically diverse oat populations: Effect of genotype unit area. Phytopathology 75:607-610.

21. Nugugi, H. K., King, S. B., Holt, J., and Julian, A. M. 2001. Simultaneous temporal progress of sorghum anthracnose and leaf blight in crop mixtures with disparate patterns. Phytopathology 91:720-729.

22. Ou, S. H. 1985. Rice Diseases, 2nd ed. CMI, Kew, UK.

23. Qiu, W. F., Wu, Y. S., Fan, H. Z., Rong, W. Z., and Zeng, S. M. 1986. Agricultural Plant Pathology. China Agricultural Press, Beijing.

24. Robinson, R. A. 1976. Plant Pathosystems. Springer-Verlag, New York.

25. Smithson, J. B., and Lenne, J. M. 1996. Varietal mixtures: A viable strategy for sustainable productivity in subsistence agriculture. Ann. Appl. Biol. 128:127-158.

26. Suzuki, H. 1975. Meteorological factors in the epidemiology of rice blast. Annu. Rev. Phytopathol. 13:239-256.

27. Wolfe, M. S. 1985. The current status and prospects of multiline cultivars and variety mixtures for disease resistance. Annu. Rev. Phytopathol. 23:251-273.

28. Wolfe, M. S., and Barrett, J. A. 1980. Can we lead the pathogen astray? Plant Dis. 64:148-155.

29. Xu, Z. G., Zheng, H. B., Li, H. F., Shang, H. S., Liu, W. Z., and Fang, Z. D. 1997. General Plant Pathology, 2nd ed. China Agricultural Press, Beijing.

30. Yang, X. M., Li, G. Q., Wang, J. G., Li, L. L., Li, X., and Zheng, L. S. 2000. Plant Ecological Phytopathology. China Agricultural Science and Technology Press, Beijing.

31. Zhu, Y., Chen, H., Fan, J., Wang, Y., Li, Y., Chen, J., Fan, J.-X., Yang, S., Hu, L., Leung, H., Mew, T. W., Teng, P. S., Wang, Z., and Mundt, C. C. 2000. Genetic diversity and disease control in rice. Nature 406:718-722. 